JKMM, Vol. 2 No. 1, Desember 2019

\title{
PERBEDAAN PENGARUH IKLIM ORGANISASI DAN DUKUNGAN ORGANISASI TERHADAP ORGANIZATIONAL CITIZENSHIP BEHAVIOR KARYAWAN DI RS SWASTA DAN RS PEMERINTAH
}

\author{
DIFFERENCE EFFECT OF ORGANIZATIONAL CLIMATE AND \\ PERCEIVED ORGANIZATIONAL SUPPORT TOWARDS EMPLOYEE'S \\ ORGANIZATIONAL CITIZENSHIP BEHAVIOR \\ IN PRIVATE AND PUBLIC HOSPITALS
}

\author{
${ }^{1}$ Rusda Ananda, ${ }^{2}$ Indahwaty Sidin, ${ }^{3}$ Tahir Abdullah \\ ${ }^{1}$ Manajemen Administrasi Rumah Sakit, Fakultas Kesehatan Masyarakat, Universitas \\ Hasanuddin, Makassar \\ ${ }^{2}$ Manajemen Administrasi Rumah Sakit, Fakultas Kesehatan Masyarakat, Universitas \\ Hasanuddin, Makassar \\ ${ }^{3}$ Biostatistik, Fakultas Kesehatan Masyarakat, Universitas Hasanuddin, Makassar \\ Alamat Koresponden: Fakutas Kesehatan Masyarakat, Universitas Hasanuddin, 90245, \\ rusdaananda28@yahoo.com
}

\begin{abstract}
Abstrak
Rumah sakit dalam menyelenggarakan pelayanan kesehatan yang berkualitas membutuhkan sumber daya manusia yang memiliki komitmen terhadap organisasi sehingga perlu iklim organisasi dan dukungan organisasi yang tepat agar karyawan memiliki organizational citizenship behavior (OCB) yang tinggi. Penelitian ini bertujuan untuk melihat perbedaan pengaruh iklim organisasi dan dukungan organisasi terhadap OCB karyawan di rumah sakit swasta dan pemerintah. Penelitian dilakukan di RS Stella Maris dan RS Universitas Hasanuddin Kota Makassar. RS Stella Maris dipilih sebagai representasi rumah sakit swasta dan RS Universitas Hasanuddin sebagai respresentasi rumah sakit pemerintah. Responden penelitian merupakan tenaga medis dan non medis yang dipilih berdasarkan teknik probability sampling melalui simple random sampling. Total sampel dalam penelitian ini sebanyak 170 karyawan rumah sakit yang terdiri dari 83 responden dari rumah sakit swasta dan 87 responden dari rumah sakit pemerintah. Hasil penelitian menunjukkan bahwa iklim organisasi berpengaruh signifikan terhadap OCB karyawan di RS Stella Maris. Selain itu iklim organisasi juga berpengaruh signifikan terhadap OCB karyawan di RS Universitas Hasanuddin. Selain iklim organisasi, dukungan organisasi juga berpengaruh signifikan terhadap OCB karyawan di RS Stella Maris. Begitu pula di RS Universitas Hasanuddin dimana dukungan organisasi berpengaruh secara signifikan terhadap OCB karyawan. Iklim organisasi tidak memiliki perbedaan pengaruh di RS Stella Maris dan RS Universitas Hasanuddin. Sebaliknya, dukungan organisasi memiliki perbedaan pengaruh di Stella Maris dan RS Universitas Hasanuddin. Sebagai kesimpulan, iklim organisasi dan dukungan organisasi masing-masing berpengaruh signifikan terhadap OCB karyawan di RS Stella Maris dan RS Universitas Hasanuddin, namun ada perbedaan pengaruh dukungan organisasi terhadap OCB karyawan pada kedua rumah sakit tersebut.
\end{abstract}

Kata Kunci: organizational citizenship behavior, iklim organisasi, dukungan organisasi 


\begin{abstract}
Hospitals in providing quality health services require human resources who have a commitment to the organization so that it needs an appropriate organizational climate and perceived organizational support in order employees have high organizational citizenship behavior (OCB). This study aims to identify the difference effect of organizational climate and perceived organizational support on employees' OCB in private and public hospitals. The study was conducted at Stella Maris Hospital and Hasanuddin University Hospital located in the City of Makassar. Stella Maris Hospital was chosen as a representation of private hospitals and Hasanuddin University Hospital as a representation of public hospitals. Respondents of this study were medical and non-medical staff who were selected based on probability sampling techniques through simple random sampling. The total sample in this study were 170 hospital employees consisting of 83 respondents from private hospitals and 87 respondents from public hospitals. The results showed that organizational climate had a significant effect on employees' OCB at Stella Maris Hospital. In addition, the organizational climate also has a significant effect on employees' OCB at Hasanuddin University Hospital. Besides that, perceived organizational support also had a significant effect on employees' OCB at Stella Maris Hospital. Perceived organizational suppport at Hasanuddin University Hospital also had a significant effect on employees' $O C B$. The organizational climate did not have a difference effect on employees' OCB at Stella Maris Hospital and Hasanuddin University Hospital. However, perceived organizational support had difference effect on employees' OCB at Stella Maris Hospital and Hasanuddin University Hospital. As a conclusion, organizational climate and perceived organizational support each of them had a significant effect on employees' OCB at Stella Maris Hospital and Hasanuddin University Hospital, but there were difference effect of perceived organizational support on employees' OCB in both hospitals.
\end{abstract}

Keywords: organizational citizenship behavior, organizational climate, perceived organizational support 


\section{PENDAHULUAN}

Organisasi saat ini harus terus bertumbuh dan berkembang untuk dapat bertahan dan menghadapi persaingan, begitu pun dengan institusi kesehatan seperti rumah sakit. Organisasi tidak hanya dituntut untuk memiliki produktivitas yang tinggi namun juga harus menyediakan kondisi lingkungan yang aman dan sehat. Lingkungan yang berubah dengan cepat serta perkembangan informasi yang pesat membutuhkan orangorang yang berdedikasi tinggi untuk kelangsungan hidup organisasi.

Untuk itu, dibutuhkan karyawan yang memiliki komitmen terhadap organisasi yang salah satunya dapat direfleksikan melalui organizational citizenship behavior (OCB), yaitu perilaku kerja yang bebas dilakukan (bersifat sukarela), tidak berkaitan dengan sistem penghargaan secara formal dan merupakan satu kesatuan yang dapat meningkatkan efektivitas organisasi (Organ, 1988). OCB karyawan merupakan perilaku yang dilakukan sebagai pekerjaan tambahan dan bukan merupakan tugas utama seorang karyawan di tempat kerja (Schermerhorn et al., 2010).

Tingginya tingkat OCB karyawan dinilai berpengaruh secara signifikan terhadap peningkatan kinerja organisasi
(Bhatla, 2017; Mallick et al., 2015; Organ, 2017; Podsakoff \& Mackenzie, 1997; Romle et al., 2016). OCB sangat bergantung pada usaha karyawan (Virkkunen, 2016). Melalui peningkatan OCB, karyawan dapat melakukan evaluasi dan mengetahui kinerjanya dalam organisasi (Coole, 2003). Tanpa adanya perilaku tersebut, organisasi akan sulit untuk bertahan dan mencapai hasil yang baik (Srivastava \& Gope, 2015).

Berdasarkan beberapa kajian literatur, faktor anteseden yang signifikan terhadap peningkatan OCB antara lain adalah kejelasan peran, kepemimpinan, dorongan motivasi, kepuasan kerja dan komitmen organisasi (Chahal \& Mehta, 2010), karakteristik individu (Chahal \& Mehta, 2010; Suresh \& Venkatammal, 2010), perlakuan adil (Chahal \& Mehta, 2010; Ehigie \& Otukoya, 2005), iklim organisasi (Suresh \& Venkatammal, 2010), dan dukungan organisasi (Ehigie \& Otukoya, 2005). Faktor anteseden tersebut dapat dikelompokkan menjadi faktor yang berfokus pada organisasi dan faktor yang berfokus pada individu. Iklim organisasi dan dukungan organisasi merupakan faktor yang berfokus pada organisasi sehingga melihat segala sesuatunya lebih komprehensif. Sementara 
faktor yang lain cenderung fokus pada karyawan secara personal.

Iklim organisasi dan dukungan organisasi merupakan faktor yang menjadi representasi untuk menciptakan lingkungan organisasi yang sehat, aman, inovatif, dan efektif (Törner et al., 2016). Pemahaman tentang iklim organisasi sangat dibutuhkan untuk mendasari peningkatan terhadap kualitas pelayanan (Shamoradi, 2016). Iklim organisasi terbentuk dari kumpulan pengalaman dan perasaan karyawan terhadap organisasinya (Schneider, 2000) serta bagaimana organisasi memahami kondisi psikologis karyawan (Ostroff et al., 2011). Hal ini berhubungan dengan persepsi, perasaan, dan perilaku karyawan di organisasi atau tempat kerjanya. Sehingga iklim organisasi dapat didefinisikan sebagai persepsi karyawan terhadap kondisi atau karakteristik organisasi yang berlangsung secara terus menerus (Schneider \& Bartlett, 1968).

Selain iklim organisasi yang dimaknai sebagai sekumpulan pengalaman orangorang yang terjadi di lingkungan organisasi (Schneider et al., 2013), dukungan organisasi juga dibutuhkan untuk meningkatkan kemampuan serta kinerja individu yang berada di dalamnya (Tsai et al., 2015). Dukungan organisasi berdampak pada komitmen karyawan terhadap organisasi (Rhoades \& Eisenberger, 2002) dan OCB (Chen et al., 2009) terbukti sangat berpengaruh terhadap OCB (Chiaburu et al., 2015). Dukungan organisasi adalah persepsi karyawan terhadap bagaimana organisasi menghargai kontribusi dan peduli terhadap kesejahteraan mereka (Eisenberger et al., 1986). Penelitian ini bertujuan untuk mengetahui perbedaan pengaruh iklim organisasi dan dukungan organisasi terhadap OCB karyawan di RS Swasta dan RS Pemerintah Kota Makassar.

\section{BAHAN DAN METODE}

\section{Lokasi dan Rancangan Penelitian}

Penelitian dilakukan di Rumah Sakit Stella Maris yang merupakan rumah sakit swasta dan Rumah Sakit Universitas Hasanuddin yang merupakan rumah sakit Pemerintah di Kota Makassar, Sulawesi Selatan. Penelitian ini merupakan penelitian kuantitatif dengan menggunakan rancangan observasional analitik dan pendekatan crosssectional.

\section{Populasi dan Sampel}

Populasi dalam penelitian ini adalah karyawan Rumah Sakit Stella Maris yang berjumlah 560 orang dan karyawan Rumah Sakit Universitas Hasanuddin yang berjumlah 834 orang. Teknik penentuan 
sampel menggunakan probability sampling melalui simple random sampling. Jumlah sampel di RS Universitas Hasanuddin sebanyak 87 karyawandan jumlah sampel di RS Stella Maris sebanyak 83 karyawan. Sehingga total sampel dalam penelitian ini sebanyak 170 karyawan.

\section{Metode Pengumpulan Data}

Pengumpulan data dilakukan dengan instrumen penelitian berupa kuesioner yang terbagi atas identitas umum responden, variabel iklim organisasi, variabel dukungan organisasi, dan variabel OCB. Identitas umum responden terdiri dari umur, jenis kelamin, tingkat pendidikan, masa kerja, profesi, unit kerja, dan status kepegawaian. Variabel OCB diukur dengan menggunakan lima dimensi yang dikemukakan oleh Organ (1988) yakni altruism, conscientiousness, courtesy, civic virtue, dan sportsmanship. Variabel iklim organisasi diukur dengan menggunakan instrumen yang dikembangkan oleh para peneliti MeS (Laboratory of Management e Sanita) yang digunakan untuk mengukur iklim organisasi di RS Swasta dan Pemerintah wilayah Tuscany, Italia (Rojas et al., 2013). Variabel dukungan organisasi diukur dengan menggunakan alat ukur yang dikembangkan oleh Eisenberger et al., (1986), yaitu Survey Perceived Organizational Support (SPOS).

\section{Analisis Data}

Pengolahan dan analisis data dilakukan dengan menggunakan aplikasi komputer SPSS (Statistical Package for the Social Sciences). Analisis data menggunakan analisis univariat dan bivariat. Untuk analisis bivariat dilakukan melalui dua tahap. Pertama dilakukan analisis regresi linier untuk mengetahui masing-masing pengaruh variabel iklim organisasi dan dukungan organisasi terhadap OCB karyawan di rumah sakit swasta dan pemerintah. Sselanjutnya dilakukan uji beda melalui uji $\mathrm{T}$ dengan alternatif uji Mann-Whitney untuk mengetahui perbedaan pengaruh masingmasing variabel variabel iklim organisasi dan dukungan organisasi terhadap OCB karyawan di rumah sakit swasta dan pemerintah.

\section{HASIL}

\section{Karakteristik Sampel}

Tabel 1 menunjukkan karakteristik umum responden terdiri atas umur, jenis kelamin, tingkat pendidikan, masa kerja, dan status kepegawaian. Berdasarkan karakteristik umur, sebagian besar karyawan yang bekerja baik di RS Stella Maris maupun di RS Universitas Hasanuddin merupakan karyawan dengan kategori umur dewasa (26 -45 tahun). Karyawan dewasa 
di RS Stella Maris memiliki persentase sebanyak 75,9\% sementara di RS Universitas Hasanuddin sebanyak 92\%.Berdasarkan jenis kelamin, responden perempuan mendominasi baik di RS Stella Maris $(80,7 \%)$ maupun di RS Universitas Hasanuddin (77\%). Berdasarkan tingkat pendidikan, di RS Stella Maris sebagian besar responden memiliki latar belakang pendidikan D3 $(45,8 \%)$ sedangkan di RS Unhas sebagian besar responden memiliki latar belakang pendidikan S1 $(66,7 \%)$.

Berdasarkan masa kerja, sebagian besar responden telah bekerja selama rentang waktu 1 - 5 tahun di kedua rumah sakit baik di RS Stella Maris $(38,6 \%)$ dan RS Universitas Hasanuddin (55,2\%). Berdasarkan status kepegawaian sebagian besar responden merupakan karyawan dengan status kepegawaian lainnya dalam hal ini sebagai tenaga kerja tetap $(73,5 \%)$ di RS Stella Maris dan tidak ada tenaga PNS karena RS tersebut merupakan instansi milik swasta. Sementara di RS Universitas Hasanuddin sebagian besar responden berstatus karyawan kontrak $(74,7 \%)$ dan $25,3 \%$ merupakan karyawan dengan status PNS.

Tabel 1. Karakteristik Umum Responden

\begin{tabular}{|c|c|c|c|c|c|c|c|}
\hline \multirow{2}{*}{ No. } & \multirow{2}{*}{ Karakteristik } & \multicolumn{2}{|c|}{ RS Stella Maris } & \multicolumn{2}{|c|}{$\begin{array}{l}\text { RS Universitas } \\
\text { Hasanuddin }\end{array}$} & \multicolumn{2}{|c|}{ Total } \\
\hline & & $\mathbf{n}$ & $\%$ & $\mathbf{n}$ & $\%$ & $\mathbf{n}$ & $\%$ \\
\hline 1. & Kelompok Umur & & & & & & \\
\hline a. & Remaja ( $\leq 25$ tahun) & 13 & 15,7 & 6 & 6,9 & 19 & 11,2 \\
\hline b. & $\begin{array}{l}\text { Dewasa }(26-45 \\
\text { tahun) }\end{array}$ & 63 & 75,9 & 80 & 92 & 143 & 84,1 \\
\hline c. & $\begin{array}{l}\text { Lansia (46-65 } \\
\text { tahun) }\end{array}$ & 7 & 8,4 & 1 & 1,1 & 8 & 4,7 \\
\hline 2. & Jenis Kelamin & & & & & & \\
\hline a. & Laki-laki & 16 & 19,3 & 20 & 23 & 36 & 21,2 \\
\hline b. & Perempuan & 67 & 80,7 & 67 & 77 & 134 & 78,8 \\
\hline 3. & Tingkat Pendidikan & & & & & & \\
\hline a. & SMA & 13 & 15,7 & 3 & 3,4 & 16 & 9,4 \\
\hline b. & D3 & 38 & 45,8 & 16 & 18,4 & 54 & 31,8 \\
\hline c. & $\mathrm{S} 1$ & 32 & 38,5 & 58 & 66,7 & 90 & 52,9 \\
\hline d. & $\mathrm{S} 2$ & 0 & 0 & 10 & 11,5 & 10 & 5,9 \\
\hline 4. & Masa Kerja & & & & & & \\
\hline a. & $<1$ tahun & 7 & 8,4 & 4 & 4,6 & 11 & 6,5 \\
\hline b. & $1-5$ tahun & 32 & 38,6 & 48 & 55,2 & 80 & 47,1 \\
\hline c. & $6-10$ tahun & 20 & 24,1 & 35 & 40,2 & 55 & 32,4 \\
\hline d. & $>10$ tahun & 24 & 28,9 & 0 & 0 & 24 & 14,1 \\
\hline & Status Kepegawaian & & & & & & \\
\hline a. & PNS & 0 & 0 & 22 & 25,3 & 22 & 12,9 \\
\hline b. & Kontrak & 19 & 22,9 & 65 & 74,7 & 84 & 49,4 \\
\hline c. & Honorer & 3 & 3,6 & 0 & 0 & 3 & 1,8 \\
\hline d. & Lainnya & 61 & 73,5 & 0 & 0 & 61 & 35,9 \\
\hline
\end{tabular}


Analisis Bivariat

Tabel 2 menunjukkan nilai signifikansi variabel iklim organisasi di RS Stella Maris sebesar $0,000<0,05$ artinya iklim organisasi berpengaruh signifikan terhadap tingkat OCB karyawan di RS Stella Maris. Begitu pula dengan nilai signifikansi iklim organisasi di RS Universitas Hasanuddin sebesar $0,000<0,05$ artinya iklim organisasi berpengaruh signifikan terhadap tingkat OCB karyawan di RS Universitas Hasanuddin. Selanjutnya untuk variabel dukungan organisasi, nilai signifikansi di RS Stella Maris 0,019 < 0,05 begitu pula dengan RS Universitas Hasanuddin dimana nilai signifikansi 0,000 < 0,05. Hal tersebut menunjukkan bahwa dukungan organisasi berpengaruh signifikan terhadap tingkat OCB karyawan di RS Stella Maris dan RS Universitas Hasanuddin.

Tabel 2. Pengaruh Iklim Organisasi dan Dukungan Organisasi terhadap Organizational Citizenship Behavior Karyawan di RS Stella Maris dan RS Universitas Hasanuddin Tahun 2018

\begin{tabular}{|c|c|c|c|}
\hline \multirow[t]{2}{*}{ No. } & \multirow[t]{2}{*}{ Variabel } & $\begin{array}{c}\text { RS } \\
\text { Stella } \\
\text { Maris }\end{array}$ & $\begin{array}{c}\text { RS } \\
\text { Universitas } \\
\text { Hasanuddin }\end{array}$ \\
\hline & & $\begin{array}{l}\text { Sig. (P } \\
\text { value) }\end{array}$ & $\begin{array}{l}\text { Sig. (P } \\
\text { value })\end{array}$ \\
\hline 1. & $\begin{array}{l}\text { Iklim } \\
\text { Organisasi }\end{array}$ & 0,000 & 0,000 \\
\hline 2. & $\begin{array}{l}\text { Dukungan } \\
\text { Organisasi }\end{array}$ & 0,019 & 0,000 \\
\hline
\end{tabular}

Tabel 3 menunjukkan bahwa tidak ada perbedaan pengaruh iklim organisasi terhadap OCB karyawan di RS Stella Maris dan RS Universitas Hasanuddin (0,069 > 0,05), sedangkan pada variabel dukungan organisasi menunjukkan bahwa ada perbedaan pengaruh dukungan organisasi terhadap OCB karyawan di RS Stella Maris dan RS Universitas Hasanuddin $(0,048<$ $0,05)$.

Tabel 3. Perbedaan Pengaruh Iklim Organisasi dan Dukungan Organisasi terhadap Organizational Citizenship Behavior Karyawan di RS Stella Maris dan RS Universitas Hasanuddin Tahun 2018

\begin{tabular}{clc}
\hline No. & \multicolumn{1}{c}{ Variabel } & Sig. (P value $)$ \\
\hline 1. & Iklim Organisasi & 0,069 \\
\hline 2. & $\begin{array}{l}\text { Dukungan } \\
\text { Organisasi }\end{array}$ & 0,048 \\
\hline
\end{tabular}

\section{PEMBAHASAN}

Dalam penelitian ini terlihat bahwa baik iklim organisasi maupun dukungan organisasi pada RS Stella Maris dan RS Universitas Hasanuddin masing-masing berpengaruh secara signifikan terhadap peningkatan OCB karyawan rumah sakit. Namun ada perbedaan pengaruh masingmasing variabel tersebut terhadap OCB karyawan. Secara statistik, iklim organisasi tidak memiliki perbedaan pengaruh yang signifikan terhadap peningkatan OCB 
Ananda, 2019

karyawan di RS Stella Maris dan RS Universitas Hasanuddin. Sedangkan dukungan organisasi memiliki perbedaan pengaruh yang signifikan terhadap peningkatan OCB karyawan di RS Stella Maris dan RS Universitas Hasanuddin.

Iklim organisasi dapat dimaknai sebagai bentuk interaksi orang-orang melalui sejumlah pengalaman yang dimiliki di tempat kerja (Schneider et al., 2013). Iklim organisasi membedakan organisasi yang satu dengan organisasi yang lain yang berlangsung terus-menerus, dan mempengaruhi perilaku orang-orang dalam organisasi (Forehand \& Gilmer, 1964). Iklim organisasi terbentuk melalui berbagai pengamatan dan pengalaman (Schneider et al., 2017).Iklim organisasi di RS Stella Maris berpengaruh signifikan terhadap tingkat OCB karyawan. Begitu pula hasil penelitian di RS Universitas Hasanuddin menunjukkan hasil sama. Semakin mendukung iklim organisasi pada sebuah rumah sakit, maka akan semakin memicu karyawan untuk meningkatkan perilaku yang selalu bersedia membantu atau berpartisipasi dalam kegiatan-kegiatan yang bukan termasuk tuposinya serta bersedia membantu tanpa diminta bantuan terlebih dahulu.

Podsakoff et al., (1990) dan Ardichvilli (2011) menyatakan salah satu dimensi iklim organisasi yang berperan penting dalam meningkatkan OCB karyawan adalah alat manajerial. Hal tersebut dapat dilihat dari persepsi karyawan terhadap organisasi dalam mengalokasikan anggaran dengan tepat, apakah karyawan mengetahui tujuan penggunaan anggaran, bagaimana karyawan dapat memonitor proses penggunaan anggaran, serta penggunaan anggaran yang membantu karyawan dalam mengerjakan tugas pokok dan fungsinya di tempat kerja.

Sejalan dengan hasil penelitian tersebut, Suresh dan Venkatammal (2010) menyatakan OCB sangat berhubungan dengan iklim organisasi. Iklim yang sehat adalah salah satu pemicu munculnya OCB karyawan dimana perilaku kerja seperti kepuasan kerja dan komitmen organisasi berperan sebagai perantara yang kuat (Lee et al., 2007).Salah satu faktor penting yang berperan dalam pengaruh iklim organisasi terhadap OCB adalah budaya yang terdapat dalam organisasi. Tempat yang berbeda menghasilkan hasil penelitian yang berbeda. Qadeer dan Jaffery (2014) dalam hasil penelitiannya menjelaskan bahwa karyawan yang merasa belum sejahtera dalam hal ekonomi dan tingginya tingkat persaingan sesama rekan kerja menyebabkan rendahnya tingkat OCB karyawan. Ketatnya persaingan 
di tempat kerja akan membuat karyawan lebih bersikap hati-hati dan sebisa mungkin tidak melanggar peraturan organisasi. Hal ini mengarah pada perilaku conscientiousness karyawan di RS Universitas Hasanuddin yang lebih tinggi dibandingkan di RS Stella Maris.

Beberapa penelitian yang tidak sejalan dengan hasil penelitian ini diantaranya penelitian yang dilakukan oleh Qadeer dan Jaffery (2014) serta Walker et al., (2010) yang menyatakan bahwa iklim organisasi tidak berpengaruh positif terhadap OCB. Hasil penelitian Turker (2008) dan Nimran (2011) juga menyatakan bahwa iklim organisasi tidak berpengaruh secara langsung terhadap OCB. Menurut Qadeer dan Jaffery (2014) iklim organisasi dapat berpengaruh terhadap OCB apabila dimediasi oleh faktor psikologi seperti atasan yang selalu bersedia memberikan arahan ketika dibutuhkan, memberikan dukungan, dan umpan balik terhadap kinerja karyawan.

Dukungan organisasi merupakan persepsi karyawan mengenai sejauh mana organisasi menilai kontribusi, memberi dukungan, dan peduli pada kesejahteraan mereka (Rhoades dan Eisenberger, 2002) sehingga karyawan merasa menjadi bagian dari organisasi dan merasa bertanggungjawab untuk berkontribusi dan memberikan kinerja terbaiknya. Hasil penelitian menunjukkan bahwa dukungan organisasi berpengaruh signifikan terhadap tingkat OCB karyawan di RS Stella Maris dan RS Universitas Hasanuddin. Sebagian besar penelitian menyatakan bahwa dukungan organisasi berpengaruh terhadap OCB. Beberapa penelitian yang sejalan tersebut menyatakan bahwa dukungan organisasi adalah salah satu faktor yang berpengaruh terhadap tingkat OCB karyawan (Singh dan Singh, 2010; Chiang dan Hsieh, 2012; Lin dan Lin, 2011; Isfahani dan Rezaei, 2017). Selain itu hasil penelitian Norris dan Porter (2017) terhadap para pekerja profesional menunjukkan bahwa dukungan organisasi sangat berpengaruh terhadap OCB karyawan terutama pada dimensi civic virtue.

Ketika organisasi mampu mewadahi partisipasi dan keinginan karyawan, hal tersebut akan membuat karyawan merasa mendapatkan dukungan dari organisasi. Selain itu karyawan juga akan bersedia untuk lebih berusaha demi kemajuan organisasi. Semakin besar dukungan organisasi, maka akan semakin banyak karyawan yang memiliki OCB yang tinggi. Meskipun begitu, hal tersebut tidak berpengaruh positif terhadap kinerja 
karyawan. Karyawan yang memiliki OCB yang tinggi belum tentu memiliki kinerja yang baik (Chiang dan Hsieh, 2012).

Penelitian lain dilakukan oleh Chen et al., (2009) pada rentang waktu yang berbeda untuk melihat pengaruh dukungan organisasi terhadap OCB karyawan sebelum dan setelah dilakukan perubahan. Hasil penelitian menunjukkan bahwa adanya perubahan dalam dukungan organisasi berpengaruh terhadap OCB karyawan. Hal ini membuktikan bahwa dukungan organisasi adalah variabel yang berpengaruh terhadap OCB karyawan.

Penelitian yang tidak sejalan dengan hasil penelitian ini adalah penelitian yang dilakukan oleh Islam et al., (2014) yang menyatakan bahwa dukungan organisasi tidak berpengaruh signifikan terhadap OCB karyawan. Dalam hal ini para manajer perlu memperkenalkan budaya dan dukungan dalam organisasi serta memperhatikan kualitas kerja karyawan karena tingginya tingkat kompetisi. Lebih lanjut dijelaskan bahwa untuk memunculkan OCB karyawan, organisasi perlu memperhatikan kepuasan kerja karyawan karena karyawan yang merasa puas dengan pekerjaannya lebih berpeluang untuk memiliki tingkat OCB yang tinggi.

Iklim organisasi berpengaruh signifikan terhadap OCB karyawan di RS Universitas Hasanuddin dan RS Stella Maris. Hal tersebut menunjukkan bahwa tidak ada perbedaan pengaruh iklim organisasi terhadap OCB karyawan di RS Stella Maris dan RS Universitas Hasanuddin. Sama halnya dengan iklim organisasi, dukungan organisasi juga berpengaruh signifikan terhadap kedua rumah sakit. Namun hasil uji statistik menunjukkan bahwa ada perbedaan pengaruh dukungan organisasi terhadap OCB karyawan di RS Stella Maris dan RS Universitas Hasanuddin. Adanya perbedaan pengaruh pada kedua jenis organisasi ini disebabkan oleh faktor yang salah satunya adalah perbedaan karakteristik rumah sakit. Hal ini menunjukkan bahwa bentuk organisasi rumah sakit berkontribusi terhadap dukungan organisasi yang diberikan kepada karyawan.

Adanya perbedaan pengaruh dukungan organisasi terhadap OCB karyawan salah satunya dilihat dari upaya pihak rumah sakit dalam menjaga kepuasan kerja karyawan. Di RS Universitas Hasanuddin tidak ada program khusus terkait kepuasan karyawan baik itu berupa survei atau kegiatan rutin yang dapat menjaga karyawab untuk tetap merasa puas bekerja di tempat tersebut. Sementara di RS 
Stella Maris, organisasi memperhatikan kepuasan kerja karyawan dengan selalu berupaya menyediakan lingkungan yang nyaman untuk bekerja sehingga karyawan merasa bahwa organisasi mampu membaca dan memenuhi kebutuhan karyawan di tempat kerja.

Hal ini kemudian berdampak pada proses pemberian layanan kepada pasien dimana pasien lebih puas terhadap kualitas pelayanan di rumah sakit swasta dibandingkan dengan rumah sakit pemerintah karena pelayanan yang diberikan karyawan rumah sakit yaitu dokter dan perawat serta staf lain yang melayani mereka berbeda (Taner \& Antony, 2006).

Selain kepuasan pengguna layanan kesehatan, penelitian yang dilakukan Rojas et al., (2013) juga menyatakan bahwa ada perbedaan tingkat kepuasan kerja antara karyawan di rumah sakit swasta dan pemerintah. Karyawan di rumah sakit swasta dinilai lebih puas bekerja dibandingkan dengan karyawan di rumah sakit pemerintah. Hal tersebut dikarenakan rumah sakit swasta memperhatikan kondisi kesejahteraan ekonomi karyawannya sehingga hal tersebut membuat mereka sangat termotivasi. Sementara di rumah sakit pemerintah, atasan fokus pada pencapaian tujuan organisasi dan selalu berusaha untuk memberikan pelayanan yang dapat menarik minat pelanggan dalam hal ini pasien dan keluarga pasien yang akan memanfaatkan pelayanan kesehatan.

\section{KESIMPULAN DAN SARAN}

Kesimpulan dari hasil penelitian ini adalah iklim organisasi dan dukungan organisasi masing-masing berpengaruh secara signifikan terhadap peningkatan OCB karyawan di RS Stella Maris dan RS Universitas Hasanuddin. Hasil uji beda menunjukkan tidak ada perbedaan pengaruh iklim organisasi terhadap peningkatan OCB karyawan di RS Stella Maris dan RS Universitas Hasanuddin. Sedangkan dukungan organisasi menunjukkan ada perbedaan pengaruh terhadap peningkatan OCB karyawan di RS Stella Maris dan RS Universitas Hasanuddin. Penting bagi rumah sakit untuk menjaga kepuasan kerja karyawan agar produktifitas dan kinerja dapat selalu berada pada level maksimal. Oleh karena itu disarakan kepada pihak rumah sakit untuk melakukan survei kepuasan karyawan secara berkala. Hal tersebut dapat dilakukan secara internal maupun eksternal untuk mengetahui harapan dan keinginan karyawan yang dapat membuat produktifitas bekerja meningkat. 


\section{DAFTAR PUSTAKA}

Ardichvili, A. (2011). Invited Reaction MetaAnalysis of the impact of psychologicalcapital on employee attitudes, behaviors and performance. Human Resource Development Quarterly, 22(2), 153-156.

Bhatla, N. (2017). The Effect of Dimensions of the Organizational Citizenship Behavior on performance of employees in Finance Sector with special reference to Banking sector in Lucknow.Asian Journal of Multidisciplinary Studies, 5(4), 152-160.

Chahal, H., \& Mehta, S. (2010). Antecedents and Consequences of Organisational Citizenship Behaviour (OCB): A Conceptua; Framework in Reference to Health Care Sector. Journal of Services Research, 10(2), 25-44.

Chen, Z., Eisenberger, R., Johnson, K., Sucharski, I., \& Aselage, J. (2009). Perceived organizational support and extra-role performance: Which leads to which? Journal of Social Psychology, 149(1), 119-124.

Chiaburu, D. S., Chakrabarty, S., Wang J., Li N. (2015). Organizational Support and Citizenship Behaviors: A Comparative Cross-Cultural Meta-Analysis. Management International Reviewer, 55 (5), 707-736.

Chiang, C., F., \& Hsieh, T., S. (2012). The impact of perceived organizational support and psychology empowerment on job performance: The mediating effects of organizational citizenship behavior. International Journal of Hospitality Management, 31(1), 180190.

Coole, D. R. (2003). The effects of citizenship performance, task performance, and rating format on performance judgments. University of South Florida.

Ehigie, B. O., \& Wahab, O. (2005).
Antecedents of organizational citizenship behaviour in a governmentowned enterprise in Nigeria. European Journal of Work and Organizational Psychology, 14(4), 389-399.

Eisenberger, R., Huntington, R., Hutchison, S., \& Sowa, D. (1986). Perceived Organizational Support. Journal of Applied Psychology, 71(3), 500-507.

Forehand, G.A., and Gilmer, V., H. (1964) Environmental variations in studies of organisational behaviour. Psychological Bulletin, 62, 361-382.

Isfahani, A. N., \& Rezaei, A. (2017). The Impact of Perceived Organizational Support on Organizational Citizenship Behavior: the Mediating Role of Organizational Trust. International JOurnal of Business Excellence, 13(4), 441-458.

Islam, T., Ahamd, U.N.U., \& Ahmed, I. (2014). Exploring the Relationship between POS, OLC, Job Satisfaction. and OCB. Procedia-Social and Behavioral Sciences, 114, 164-169.

Lee, T. W., Hom, P., Eberly, M., Li , J. J. (2017). Managing Employee Retention and Turnover with 21th Century Ideas. Organizational Dynamics, 1-11.

Lee, T. Z., Wu, C. H., and Hong, C. W. (2007). An empirical investigation of theinfluence of safety climate on OCB in Taiwan's facilities. Journal of OrganizationalSafety and Ergonomics, 13(3), 255-269.

Li, N., Liang, J., and Crant, J. M. (2010). The role of proactive personality in job satisfaction and OCB-A relational perspective. Journal of Applied Psychology, 95(2),395-404.

Lin, J. S., and Lin, S. C. (2011). Moderating effect of organizational climate on the relationship of organizational support and service oriented OCBs. African Journal of Business Management, 5(2), 582-595. 
Mallick, E., Pradhan, R. K., Tewari, H. R., \& Jena, L. K. (2015). Organizational Citizenship Behaviour, Job Performance and HR Practices: A Relational Perspective. Management and Labour Studies, 39(4), 1-12.

Nimran, U. (2011). Relationship between individual characteristics of employees andorganizational climate with $\mathrm{OCB}$ (OCB). Journal of Basic Applied Science Research,1(11), 2310-2313.

Norris, S. E., \& Porter, T. H. (2017). The Influence of Spirituality in the Workplace and Perceived Organizational Support on Organizational Citizenship Behaviors for Strategeic Success. Encyclopedia of Strategic Leadership and Management: USA.

Organ, D. W. (2017). Organizational Citizenship Behavior: Recent Trends and Developments. Annual Review of Organizational Psychology and Organizational Behavior, 80(17), 1-12.

Organ, D. W. 1988. Organizational Citiizenship Behavior: The Good Soldier Syndrome, Lexington, MA: Lexington Books.

Ostroff, C., Kinicki, A. J., \& Tamkins, M. M. (2011). Organizational Culture and Climate. In I. B. Weiner, W. C. Borman, D. R. Ilgen, \& R. J. Klimoski (Eds.), Handbook of Psychology (12th ed., pp. 565-593). Canada: John Wiley \& Sons, Inc.

Podsakoff, P. M., \& Mackenzie, S. B. (1997). Impact of Organizational Citizenship Behavior on Organizational Performance: A Review and Suggestion for Future Research. Human Performance, 10(2), 133-151.

Podsakoff, P. M., MacKenzie, S. B., Moorman R. H., and Fetter, R. (1990).Transformational leader behaviors and their effects on followers' trust in leader, satisfactionand OCBs. Leadership Quarterly, 1(2), 107-142.
Qadeer, F., \& Jaffery, H. (2014). Mediation of Psychological Capital between Organizational Climate and Organizational Citizenship Behavior. Pakistan Journal of Commerce and Social Sciences, 8(2), 453-470.

Rhoades, L., \& Eisenberger, R. (2002). Perceived organizational support: A review of the literature. Journal of Applied Psychology, 87(4), 698-714.

Romle, A. R., Faezah, N., Talib, M., Sabrina, N., \& Shahuri, S. (2016). The relationship between organizational citizenship behavior and high performance organization from the perspective of the students in the higher education institution in, 3(5), 37-42.

Schermerhorn, J. R., Hunt, J. G., Osborn, R. N., \& Bien, M. U. (2010). Organizational Behavior (11th Editi). United States of America: John Wiley \& Sons,Inc.

Schneider, B. (2000). The psychological life of organizationas. Handbook of Organizational Culture and Climate. Thousand Oaks, CA: Sage.

Schneider, B., \& Bartlett, C. J. (1968). Individual Differences and Organizational Climate, I : The Research Plan and Questionnaire Development. Personnel Psychology, 21, 323-333.

Schneider, B., Ehrhart, M. G., \& Macey, W. H. (2013). Organizational Climate and Culture. Annual Review of Psychology, 64(1), 361-388.

Schneider, B., Ehrhart, M. G., \& Macey, W. H. (2013). Organizational Climate and Culture. Annual Review of Psychology, 64(1), 361-388.

Schneider, B., González-romá, V., Ostroff, C., West, M. A., Schneider, B., Ostroff, C., \& West, M. A. (2017). 
Organizational Climate and Culture: Reflections on the History of the Constructs in JAP. Journal of Applied Psychology, 1-16.

Shahmoradi, M., Rezaee, Z., Sheikhi, S., \& Darabian, S. (2016). The Relationship between Organizational Climate , Organizational Culture and Creativity with Job satisfaction of Librarians in Ahwaz Public Libraries. Research Journal of Psychology and Educational Sciences, 2(4), 94-101.

Singh, A., K., \& Singh, A., P. (2010). Role of Stress and Organizational Support in Predicting Organizational Citizenship Behavior. Journal of Organizational Behavior, IX(4), 7-25.

Srivastava, S. K., \& Gope, A. K. (2015). The Antecedents and Consequences of Organization Citizenship Behaviour: A Conceptual Inquiry. Management Insight, XI(2), 51-56.

Suresh, S., \& Venkatammal, P. (2010). Antecedents of Organizational Citizenship Behaviour. Journal of the Indian Academy of Applied Psychology, 36(2), 276-286.

Taner, T., \& Antony, J. (2006). Comparing public and private hospital care service quality in Turkey. Leadership in Health Services, 19(2), 1-10.

Törner, M., Pousette, A., Larsman, P., \& Hemlin, S. (2016). Coping With Paradoxical Demands Through an Organizational Climate of Perceived Organizational Support: An Empirical Study Among Workers in Construction and Mining Industry. Journal of Applied Behavioral Science, 53(1), 125.

Tsai, C. Y., Horng, J. S., Liu, C. H., \& Hu, D. C. (2015). Work environment and atmosphere: The role of organizational support in the creativity performance of tourism and hospitality organizations. International Journal of Hospitality Management, 46, 26-35.
Turker, M. (2008). OCB and organizational learning climate relationship. Lex ETScientia International Journal.

Virkkunen, V. (2016). Influence of Context on Organizational Citizenship Behavior - Qualitative Case Study on Information Security Consultants. Hanken School of Economics. Hanken School of Economics.

Walker, R. M., Damanpour, F., and Devece, C. A. (2010). Management innovation andorganizational performance- The mediating effect of performance management. Journalof Public Administration Research and Theory, 21(2), 367-386. 